\title{
The effect of older siblings on language development as a function of age difference and sex
}

[This is a pre-acceptance version of a manuscript accepted in Psychological Science]

\author{
Naomi Havron ${ }^{*}$ \\ Franck Ramus ${ }^{1}$ \\ Barbara Heude 4 \\ Anne Forhan ${ }^{4}$ \\ Alejandrina Cristia ${ }^{1}$ \\ Hugo Peyre ${ }^{1,2,3 *}$ \\ on behalf of the EDEN Mother-Child Cohort Study Group.
}

1. Laboratoire de Sciences Cognitives et Psycholinguistique, Département d'Etudes Cognitives, Ecole Normale Supérieure, EHESS, CNRS, PSL University, 75005 Paris, France.

2. INSERM UMR 1141, Paris Diderot University, Paris, France.

3. Department of Child and Adolescent Psychiatry, Robert Debré Hospital, APHP, Paris, France.

4. Early Determinants of the Child's Health and Development Team (ORCHAD), INSERM, UMR1153 Epidemiology and Biostatistics Sorbonne Paris Cité Center (CRESS), Université Paris Descartes, Paris, France.

*Corresponding author: Naomi Havron, PhD: LSCP, Département d'Etudes Cognitives, Ecole Normale Supérieure, 29 rue d'Ulm, 75005 Paris, France. Email: naomi.havron@ mail.huji.ac.il 
The number of older siblings a child has is negatively correlated with their verbal skills, perhaps due to competition for parents' attention. The current study examined the role of siblings' sex and age gap as moderating factors, reasoning that they affect older siblings' tendency to compensate for reduced parental attention. We hypothesized that children with an older sister, especially with a large age gap, have better language abilities than those with older brothers. We reanalyzed data from the EDEN cohort $(\mathrm{N}=1,154)$ and found that children with an older sister had better language skills than those with an older brother. Contrary to predictions, the age gap between siblings was not associated with language skills, and did not interact with sex. Results suggest the negative effect of older siblings on language development may be entirely due to older brothers, and invite further research on the mechanisms involved in this effect. 
The number of older siblings a child has is negatively correlated with their verbal skills, including verbal intelligence, language development measures, and educational attainment (e.g., Black, Devereux, \& Salvanes, 2005; Peyre et al., 2016). According to the resource dilution model (Blake, 1981), a family has a limited amount of resources to distribute between siblings, and the more children the family has, the less resources are allocated to each child. These resources can be material (e.g., buying books and games), or personal (e.g., providing attention or teaching). The confluence model (Zajonc \& Markus, 1975) considers siblings to be not only consumers of the family's resources, but also part of this pool of resources. According to this theory, the child's intellectual environment is made up of the mean intellectual ability in the family - children, who have lower intellectual abilities than adults, bring this mean down. Thus, having more siblings is almost always detrimental, but the older the siblings, the less detrimental their effect.

Verbal intelligence is more affected by birth order than non-verbal intelligence (Peyre et al., 2016), suggesting that the effect of older siblings is greater for language development. One possible reason for this may be that language development is more affected by the quantity and quality of input the child receives than non-verbal intelligence. Child-directed speech from adults, especially in one-on-one interactions, has been found to promote language learning (e.g., Hart \& Risley, 1995; Ramirez-Esparza, Garcia-Sierra, \& Kuhl, 2014). The relationship between number of older siblings and language development may relate to a decrease in parents' ability to spend one-on-one time with each child separately. For example, when both siblings are present, parents can be more responsive to the older child, at the expense of providing (quality) language input to the younger child (Huttenlocher, Vasilyeva, Waterfall, Vevea, \& Hedges, 2007; see also Hoff-Ginsberg, 1998).

However, can siblings themselves make up for some of this lost parental resources by providing their own input and interactions? Though children may not be as adept as adults at 
adapting their speech to younger children (Mannle, Barton, \& Tomasello, 1992), siblings are able to adjust their teaching strategies to their younger siblings' ages (Dunn \& Kendrick, 1982; Perez-Granados \& Callanan, 1997). Indeed, having older siblings positively affects: social-communicative skills (Hoff, 2006), the ability to join in conversations (Dunn \& Shatz, 1989), and some aspects of syntactic development, such as pronoun use (me-you, OshimaTakane, Goodz \& Derevensky, 1996). In addition, in research on bilingual families, older siblings are found to be effective second-language models, as their second-language skills can be better than the parents', and they tend to use the second language with their younger siblings (e.g., Bridges \& Hoff, 2014; Duncan, 2017). This suggests that input and interactions with siblings can be beneficial, at least when input from the parents is of lesser quality. Conversely, other studies have found that input from siblings does not contribute to vocabulary development of the target child and generally accounts for a very small percentage of input to children in some cultures (Shneidman, Arroyo, Levine, \& Goldin-Meadow, 2013). How can these discrepancies be resolved?

We suggest that there exist two main routes by which siblings may affect language development. By competing for parents' attention, older siblings might be depriving their younger sibling of personally-tailored child-directed input. By providing their own input, however, siblings may be able to partly make up for some lost stimulation. Finding a negative effect of having older siblings on language development could mean that, on average, the effect of competition is larger than the effect of compensation, or it could mean that older siblings are unable to compensate at all. To tease apart these two scenarios, we look into different characteristics of older siblings, namely, age gap and sex. As we describe below, there is reason to believe that older siblings' characteristics affect their ability and inclination to provide their younger siblings with their own quality input. If children whose older siblings are more likely to compensate for lost input have better language skills than children whose 
older siblings are less likely to do so, then this would suggest that some older siblings do contribute to their younger siblings' language development - that is, that compensation exists.

Age gap might have an effect on parents' ability to provide linguistic simulation. More narrowly spaced siblings might present greater competition for parental resources because of their own level of demands (as they become older they require less care and supervision). Age gap might also have an effect on the likelihood that the sibling can compensate for the loss of parental linguistic simulation (Hoff-Ginsberg \& Krueger, 1991). The older the sibling is, the more likely they are to have more developed social and linguistic skills, thus providing better input. Indeed, one study found that more narrowly spaced siblings had a larger negative effect on verbal test scores in high school than more widely spaced siblings (Powell \& Steelman Carr, 1990). As mentioned above, the confluence theory also makes this prediction. This leads us to predict that the larger the age gap between target child and sibling, the less detrimental the effect of having a sibling.

A second variable of interest is gender. Older sisters are more likely to engage in positive and nurturing behavior than older brothers (Cole \& Wayne, 1990; Tucker, Mchale, \& Crouter, 2001). Additionally, at early ages girls tend to have more advanced language skills than boys (e.g., Eriksson, et al, 2012). This advantage lasts until 5-6 years of age (Peyre et al., 2019), and sister might thus contribute better quality input, at least until they reach that age. All this leads to the prediction that having an older sister is better for one's language development than having an older brother, i.e., an effect of the older sibling sex. Additionally, when an older sister is slightly older than the target child, she is relatively young and likely not very good at providing compensatory input. In contrast, much older sisters should be better able to provide such stimulation, and might be more likely to be delegated some of the care taking of the target child, and thus be in a position to provide that stimulation. We therefore predicted that the agegap effect will be greater for older sisters than for older brothers. 
To test these predictions, we reanalysed data from the EDEN cohort, a large populationbased sample of French children. Among children who have only one older sibling, we predicted better language scores for children who have an older sister than an older brother. We predicted worse language outcomes for children who had smaller age gaps with their preceding sibling. We also predicted a steeper slope of language scores on age gap when the older sibling is a sister (a larger difference between the language scores of children with an older sister and the language scores of children with an older brother when the age gap is large than when it is small).

\section{METHOD}

\section{Study Design}

We used data from the EDEN mother-child cohort study (Heude et al., 2016), whose primary aim is to identify prenatal and early postnatal nutritional, environmental and social determinants of children's health and development. This is a longitudinal study, tracking children's development from before birth to age 11 (so far). Participants were recruited between 2003 and 2006 among pregnant women followed in Poitiers and Nancy university maternities. Exclusion criteria included history of diabetes, twin pregnancies, intention to deliver outside the university hospital or to move out of the study region within the next three years, and inability to speak French. The study was approved by the Ethical Research Committee of Bicêtre Hospital and by the Data Protection Authority. Informed written consents was obtained from parents for themselves at the time of enrolment and for the new-born after delivery. For the current study, we use language measures taken at two, three and five-to-six years of age. The EDEN cohort also contains many other cognitive measures that are non-linguistic and will thus not be part of the current analyses.

\section{Participants}


There were 1,276 eligible children with language skills available at 2, 3 or 5-6 years ${ }^{1}$. There were 1,154 children (483 with one older sibling) with language skills available at two years (for some children [ $\mathrm{N}=122]$, language skills were available at 3 and/or 5-6 years but not at 2 years), 996 (416 with one older sibling) with language skills available at three years, and 898 (381 with one older sibling) with language skills available at five-to-six years. About $46 \%$ of the older siblings were girls, and $6.88 \%$ of families were single-parent families.

Although it is difficult to accurately estimate statistical power, given that the effect size of interest is unknown, that we have multiple hypotheses, and that we have unequal sample sizes at the different ages, we estimate that this sample size is large enough to detect effects similar to those found in prior work. For example, with a minimum sample size per group of 381 (the smallest $\mathrm{N}$ in any cell) we can detect an effect size of $\mathrm{d}=0.2$ (the effect size of birth order in previous studies, e.g., Kristensen \& Bjerkedal, 2007) with 80\% power.

\section{Materials}

\section{Predictors of language skills.}

Gestational age and birth weight were collected from obstetrical records, and the older sibling's sex and age was reported by the mother at birth. Smoking status and alcohol consumption during pregnancy (units/week) were determined from the questionnaires filled by the mother during pregnancy and at delivery. Mothers completed questionnaires on partial or exclusive breastfeeding (breastfeeding initiation; Bernard et al., 2017). Both parents completed questionnaires on their age at child's birth, family income, and education level. For level of

\footnotetext{
${ }^{1}$ This is a subsample of the EDEN cohort full sample, consisting only of children with one older sibling or no older siblings. Children with more than one older sibling $(n=354)$ were excluded because additional older siblings may obscure the effects of age gap and sex of the immediately preceding older sibling. The EDEN cohort full sample included 1,907 live-born children, as described in detail elsewhere (Heude et al., 2016). Attrition rate of children at age 5 years was $41 \%$ both for the overall sample in the cohort, and for our sample of analysis.
} 
parental education at birth of the child and the household income (k€/months) at each age of testing, the averages for both parents were used in the analyses (see Statistical Analysis section below). Throughout the follow-ups, parents completed questionnaires providing information on the sex and age of children born into the family after the study started.

\section{Language skills (outcome variables).}

All tests and questionnaires described below were combined to create a single score at each age, except at age two, when only one test was conducted. Using the same data set, Peyre and colleagues have found that a single latent factor provided an excellent fit to the data at both three and five-to-six years of age (Peyre, Galera, Waerden, Hoertel, \& Bernard, 2016), thus providing a general index of language skills.

Table 1. Language tests for the different ages.

$\begin{array}{ll}\text { Age } & \text { Type of Measure } \\ \text { Two years } & \text { Parental } \\ (\text { mean }= & 24 \text { questionnaire } \\ \text { months; SD = 1). }\end{array}$

Three years Assessment by Items from the ELOLA battery (De Agostini et al., 1998), a European (mean $=38$ trained psychologists oral language test battery: months; SD = 1).

\section{Tests}

French version of the MacArthur-Bates Communicative Development Inventory [CDI-2] (Kern, Langue, Zesiger, \& Bovet, 2010). Parents were asked to indicate which words from a list of 100 their child could say spontaneously (expressive vocabulary). The score is the sum of the words produced by the child. The CDI-2 has high test-retest reliability and strong associations with the corresponding scores from the longer version (Kern et al., 2010).

oral language test battery:
- Semantic fluency, scored as the sum of the number of animals retrieved spontaneously in one minute plus the number of objects named in one minute.

- Word and nonword repetition, scored as the number of words (six items) and nonwords (six items) repeated correctly.

- Picture naming, scored as the number of pictures named correctly (ten items, e.g., "cheval" ["horse"]).

Items from the NEPSY battery (Kemp, Kirk, \& Korkman, 2001; Korkman Kirk \& Kemp, 2003), a developmental neuropsychological assessment:

- Sentence repetition, scored as the number of sentences of increasing complexity and length repeated correctly (17 items, e.g., "dors bien" ["sleep well"]).

- Comprehension of instructions, a sentence comprehension task scored as the number of correct answers by pointing at one of eight pictures (13 items, e.g., "montre moi un grand lapin" ["show me a large rabbit"]).

Ages five-to-six Assessment by Tests from the same NEPSY battery.

$($ mean $=68 \quad$ trained psychologists months; $\mathrm{SD}=2$ ). 
Items from the WPPSI-III battery (Wechsler, 1967), a developmental neuropsychological assessment:

- Information, scored as the number of correct answers (speaking or pointing) to questions that address a broad range of general knowledge topics (34 items).

- Vocabulary, scored as the number of words correctly defined (25 items).

- Word Reasoning, scored as the number of concepts correctly identified from a series of clues (28 items).

\section{Statistical Analysis}

All analyses were preregistered on the Open Science Framework (https://osf.io/pgtyx/?view only=984ff0c699ba404198a0179c5533081e) before they were performed. They were performed as preregistered, except that in the adjusted models (introduced below) we added a control factor for the effect of having a younger sibling (results without controlling for this effect were similar; see supplementary materials). Additional exploratory analyses can be found in the supplementary materials.

Language scores representing language skills at three and five-to-six years were calculated as the mean of the scores at each time point (each score was first converted into a zscore in order for each test to have the same weight).

There were few missing data on language tests at three $(5.9 \%$ in our total sample and $5.3 \%$ in the sub-sample of children with an older sibling only) and five-to-six years $(1.9 \%$ in our total sample and $1.8 \%$ of children with an older sibling only), and predictors of language skills (less than $1 \%$ in both samples of analyses). Missing data on predictors of language skills were imputed using multiple imputation $(\mathrm{N}=50)$, assuming missing data are probably not missing at random (Donders, van der Heijden, Stijnen, \& Moons, 2006). All analyses were performed using SAS 9.4 software (SAS Institute Inc). Multiple imputations were implemented using the SAS PROC MI procedure with the FCS (fully conditional specification) statement.

Analysis one: Having a sibling vs. no sibling. 
Before looking into the mediating role of sex and age gap, we checked that having an older sibling (either brother or sister) was indeed detrimental for language outcomes, as found in previous research (e.g., Black, Devereux, \& Salvanes, 2005) and by Peyre et al. (2016) when analyzing the five-to-six-year-olds' data in the same cohort.

In our sample $(\mathrm{N}=1,276)$, we performed a linear mixed regression model with language skills as dependent variable, testing age as a repeated measure (two, three and five-to-six years), and the presence of one older sibling as independent variables (participant was a random effect). A second model was adjusted for exact age at time of evaluation (continuous) and other predictors of language skills (i.e. sex, gestational age (weeks), birth weight $(\mathrm{kg})$, maternal age at delivery (years), paternal age at delivery (years), breastfeeding initiation (\%), alcohol during pregnancy (units/week), tobacco during pregnancy (\%), parental education (years), household income $(\mathrm{k} € / \mathrm{month})$, presence of younger sibling(s) at the time of evaluation). These are the main factors known to influence cognitive development which were available in the EDEN cohort study (Peyre et al., 2016).

The way we adjusted the model for these control variables was by fitting three linear models, one for each testing age, with precise age at testing as well as the control variables (but not our hypothesized predictors). We then extracted the residuals from these fitted models and combined them into one data set, which served as outcome for the mixed-effects regression analysis mentioned above. The reason the adjustment was done this way is to enable us to control for exact age at time of evaluation, which would not be possible if the adjustments were done directly within the main model.

\section{Analysis two: Sex, age gap, and interaction.}

Next, we tested our prediction of a positive effect of older sisters on language development compared to older brothers, a positive effect of a larger age gap, and stronger age gap effect for older sisters. 
In the sub-sample of children with one older sibling only $(\mathrm{N}=547)$, we performed a linear mixed regression model with language skills as dependent variable, testing age as a repeated measure, sex of the older sibling, and age gap (i.e., age difference between the two siblings) as independent variables, and the interaction between older sibling sex and age gap (participant was a random effect). In a second model we adjusted for exact age at time of evaluation and the other predictors of language skills as described above.

\section{Pre-registered follow-up analyses.}

We compared children with no sibling against children who had either an older sister or an older brother (rather than a sibling without specifying the sex, like in analysis one). This was done in order to estimate the effects of older brothers and sisters respectively, relative to the baseline of having no older sibling. We performed a linear mixed regression model with language skills as dependent variable, testing age, and the presence and sex of older sibling as independent variables (categorical with three levels: no sibling, brother, and sister - no sibling was the reference). Participant was a random effect. A second model was adjusted for exact age at time of evaluation and the other predictors of language skills as described above.

\section{RESULTS}

Characteristics of participants in the samples of analysis are presented in Table 2.

Table 2. Characteristics of participants in the analysis sample of children with zero or one older sibling.

\begin{tabular}{|c|c|c|c|}
\hline & $\begin{array}{l}\text { Children with no or one older } \\
\text { sibling }\end{array}$ & $\begin{array}{c}\text { Children without any older } \\
\text { sibling }\end{array}$ & Children with one older sibling \\
\hline & $\mathrm{N}=1,276$ & $\mathrm{~N}=729$ & $\mathrm{~N}=547$ \\
\hline & $\%$ or mean $(\mathrm{SD})$ or $[\mathrm{N}]$ & $\%$ or mean $(\mathrm{SD})$ or $[\mathrm{N}]$ & $\%$ or mean $(\mathrm{SD})$ or $[\mathrm{N}]$ \\
\hline Children with one older sibling, $\%$ & 43.3 & 0 & 100 \\
\hline Sex of the older sibling (male), $\%$ & - & - & 53.9 \\
\hline Age gap (years), mean (SD) & - & - & $3.7(2.2)$ \\
\hline Language skills at 2 years, $[N]$ & {$[1154]$} & [671] & [483] \\
\hline CDI-2, mean (SD) & $62.1(29.2)$ & $64.5(28.6)$ & $58.7(29.6)$ \\
\hline Exact age of the child at the time of CDI-2 (months), mean (SD) & $24.3(1.1)$ & $24.4(1.8)$ & $24.3(0.7)$ \\
\hline Language skills at 3 years, $N$ ] & [996] & [580] & [416] \\
\hline Semantic fluency ${ }^{\xi}$, mean (SD) & $0.0(0.8)$ & $0.1(0.8)$ & $0.0(0.8)$ \\
\hline Word and nonword repetition & $0.0(0.9)$ & $0.1(0.9)$ & $0.0(1.0)$ \\
\hline Sentence repetition, mean (SD) & $7.2(3.3)$ & $7.2(3.1)$ & $7.2(3.5)$ \\
\hline Picture naming, mean (SD) & $7.0(1.8)$ & $7.2(1.8)$ & $6.9(1.9)$ \\
\hline Comprehension of instructions, mean (SD) & $8.6(2.9)$ & $8.8(2.9)$ & $8.4(3.0)$ \\
\hline Exact age of the child at the time of tests (months), mean (SD) & $38.0(0.8)$ & $38.0(0.8)$ & $38.0(0.8)$ \\
\hline Language skills at $5-6$ years, $[N]$ & [898] & {$[517]$} & [381] \\
\hline
\end{tabular}




\begin{tabular}{|c|c|c|c|}
\hline Nonword Repetition, mean (SD) & $21.0(4.9)$ & $21.0(4.9)$ & $21.0(5.0)$ \\
\hline Sentence Repetition, mean (SD) & $15.6(4.0)$ & $15.8(3.9)$ & $15.2(4.1)$ \\
\hline Information, mean (SD) & $25.1(2.9)$ & $25.4(2.9)$ & $24.7(2.8)$ \\
\hline Vocabulary, mean (SD) & $23.8(5.6)$ & $24.3(5.6)$ & $23.2(5.6)$ \\
\hline Word Reasoning, mean (SD) & $16.3(4.7)$ & $16.6(4.6)$ & $15.8(4.8)$ \\
\hline Exact age of the child at the time of tests (months), mean (SD) & $67.9(1.8)$ & $67.9(1.7)$ & $68.0(1.9)$ \\
\hline \multicolumn{4}{|l|}{ Predictors of cognitive skills } \\
\hline Sex (male), $\%$ & 51.7 & 51.5 & 52.1 \\
\hline Gestational age (weeks), mean (SD) & $39.2(1.7)$ & $39.3(1.8)$ & $39.2(1.6)$ \\
\hline Birth weight (kg), mean (SD) & $3.26(0.51)$ & $3.22(0.51)$ & $3.30(0.50)$ \\
\hline Mother's age at delivery (years), mean (SD) & $28.5(4.5)$ & $27.3(4.4)$ & $29.9(4.3)$ \\
\hline Father's age at delivery (years), mean (SD) & $31.3(5.6)$ & $30.1(5.5)$ & $32.9(5.2)$ \\
\hline Breastfeeding initiation, \% & 73.1 & 75.6 & 69.8 \\
\hline Alcohol during pregnancy (drinks/week), mean (SD) & $0.56(1.60)$ & $0.52(1.61)$ & $0.62(1.61)$ \\
\hline Maternal smoking during pregnancy, $\%$ & 24.8 & 26.3 & 23.0 \\
\hline Parental education (years), mean (SD) & $13.6(2.3)$ & $13.6(2.3)$ & $13.6(2.4)$ \\
\hline Household income at 2 years $(\mathrm{k} €)$, mean $(S D)$ & $2.61(1.01)$ & $2.53(1.00)$ & $2.71(1.01)$ \\
\hline Younger sibling(s) at 2 years, $\%$ & 8.4 & 13.1 & 2.6 \\
\hline Younger sibling(s) at 3 years, $\%$ & 20.1 & 28.4 & 9.5 \\
\hline Younger sibling(s) at 5-6 years, $\%$ & 35.2 & 47.1 & 19.7 \\
\hline Center (Nancy), $\%$ & 50.1 & 46.9 & 54.3 \\
\hline
\end{tabular}

\section{Confirmatory Analysis One - Sibling vs. no Sibling}

As predicted, language skills of children with one older sibling were lower than those of children without an older sibling (Cohen's $d=-0.14$ and -0.17 in the unadjusted and adjusted models respectively, see Table 3 and Fig. 1).

Table 3. Linear mixed regression models with language skills as dependent variable and the presence of an older sibling as independent variable $(\mathrm{N}=1,276)$.

\begin{tabular}{|c|c|c|c|}
\hline & \multicolumn{3}{|c|}{$\begin{array}{l}\text { Language scores } \# \\
\text { At } 2 \text { years: } \mathrm{N}=1154 \text { (with an older sibling: } \mathrm{N}=483 \text { ) } \\
\text { At } 3 \text { years: } \mathrm{N}=996 \text { (with an older sibling: } \mathrm{N}=416 \text { ) } \\
\text { At } 5-6 \text { years: } \mathrm{N}=898 \text { (with an older sibling: } \mathrm{N}=381 \text { ) }\end{array}$} \\
\hline & $\beta$ & SD & p-value \\
\hline \multicolumn{4}{|l|}{ Unadjusted model } \\
\hline Older sibling (ref:: without an older sibling) & -0.141 & 0.030 & $<0.0001$ \\
\hline \multicolumn{4}{|l|}{ Adjusted model $¥ 1$} \\
\hline Older sibling (ref.: without an older sibling) & -0.168 & 0.037 & $<0.0001$ \\
\hline
\end{tabular}

In bold: p-value < 0.05. \# Z-scores. ¥1 Adjusted for exact age at time of evaluation and other predictors of cognitive development (i.e. sex, gestational age (weeks), birth weight (kg), maternal age at delivery (years), paternal age at delivery (years), breastfeeding initiation (\%), alcohol during pregnancy (units/week), tobacco during pregnancy (\%), parental education (years), household income (k€/month), presence of younger sibling(s) at the time of evaluation).

Figure 1. Language skills of children with no older siblings compared to those with one older sibling. The box encompasses the inter quartile range, the black star is the mean and the bars are 2 standard deviations Since the model included children's scores at each age separately, each child has between one and three data points, depending on whether they have missing data. 


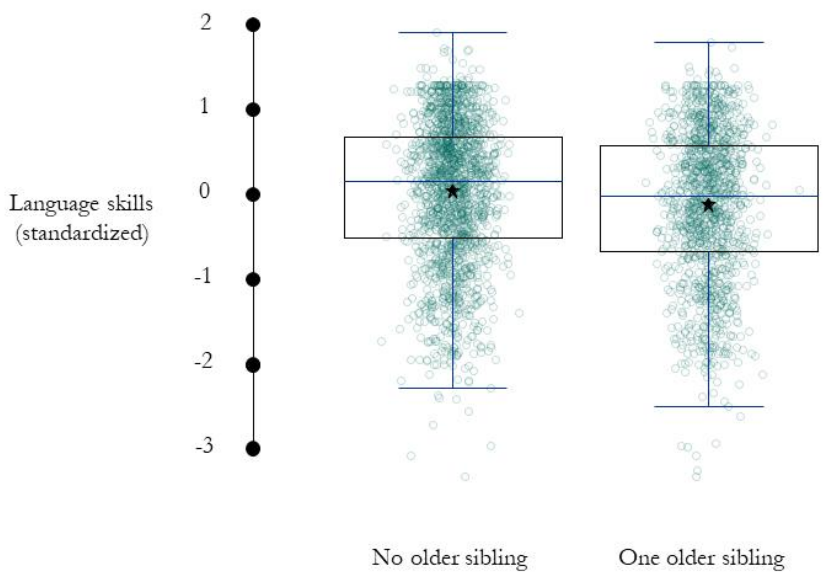

\section{Confirmatory Analysis two - Sex, Age Gap and an Interaction}

As predicted, language skills of children with an older sister were higher than those of children with an older brother $(\mathrm{d}=0.26$ and 0.22 in the unadjusted and adjusted models respectively, see Table 4 and Figs. 2 and 3).

Table 4. Linear mixed regression models with language skills as dependent variable and the sex of the older sibling, the age difference between the two siblings and the interaction between these two variables $(\mathrm{N}=547)$.

\begin{tabular}{|c|c|c|c|}
\hline \multirow[b]{3}{*}{ Unadjusted model } & \multicolumn{3}{|c|}{$\begin{array}{l}\text { Language scores\# } \\
\text { At } 2 \text { years: } \mathrm{N}=483 \text { (older sister: } \mathrm{N}=222 \text { ) } \\
\text { At } 3 \text { years: } \mathrm{N}=416 \text { (older sister: } \mathrm{N}=187 \text { ) } \\
\text { At } 5-6 \text { years: } \mathrm{N}=381 \text { (older sister: } \mathrm{N}=177 \text { ) }\end{array}$} \\
\hline & \multirow[t]{2}{*}{$\beta$} & \multirow[t]{2}{*}{ SD } & \multirow[t]{2}{*}{$\mathrm{p}$-value } \\
\hline & & & \\
\hline Sex of the older sibling (male; ref.: female) & -0.259 & 0.091 & 0.0045 \\
\hline Age gap (years) & -0.048 & 0.016 & 0.0031 \\
\hline Age gap $*$ Sex of the older sibling & 0.020 & 0.021 & 0.3543 \\
\hline \multicolumn{4}{|l|}{ Adjusted mode\1 } \\
\hline Sex of the older sibling (male; ref.: female) & -0.218 & 0.108 & 0.0433 \\
\hline Age gap (years) & -0.035 & 0.019 & 0.0708 \\
\hline Age gap $*$ Sex of the older sibling & 0.008 & 0.025 & 0.7411 \\
\hline
\end{tabular}


In bold: $\mathrm{p}$-value $<0.05$. \# Z-scores. ¥1 Adjusted for exact age at time of evaluation and other predictors of cognitive development (i.e. sex, gestational age (weeks), birth weight (kg), maternal age at delivery (years), paternal age at delivery (years), breastfeeding initiation (\%), alcohol during pregnancy (units/week), tobacco during pregnancy (\%), parental education (years), household income (k€/month), presence of younger sibling(s) at the time of evaluation).

Contrary to our prediction, language skills were negatively associated with age gap in the unadjusted model $(\mathrm{d}=-0.05, \mathrm{p}=0.003)$. This association was not significant in the model adjusted for the other predictors of language skills $(d=-0.04, p=0.071)$. No significant interaction between the sex of the older sibling and age gap was found (see Figure 2).

Figure 2. Relationships between language skills and age difference between the two siblings (months), depending on the sex of the older sibling. Dotted lines mark the $95 \mathrm{CI}$.

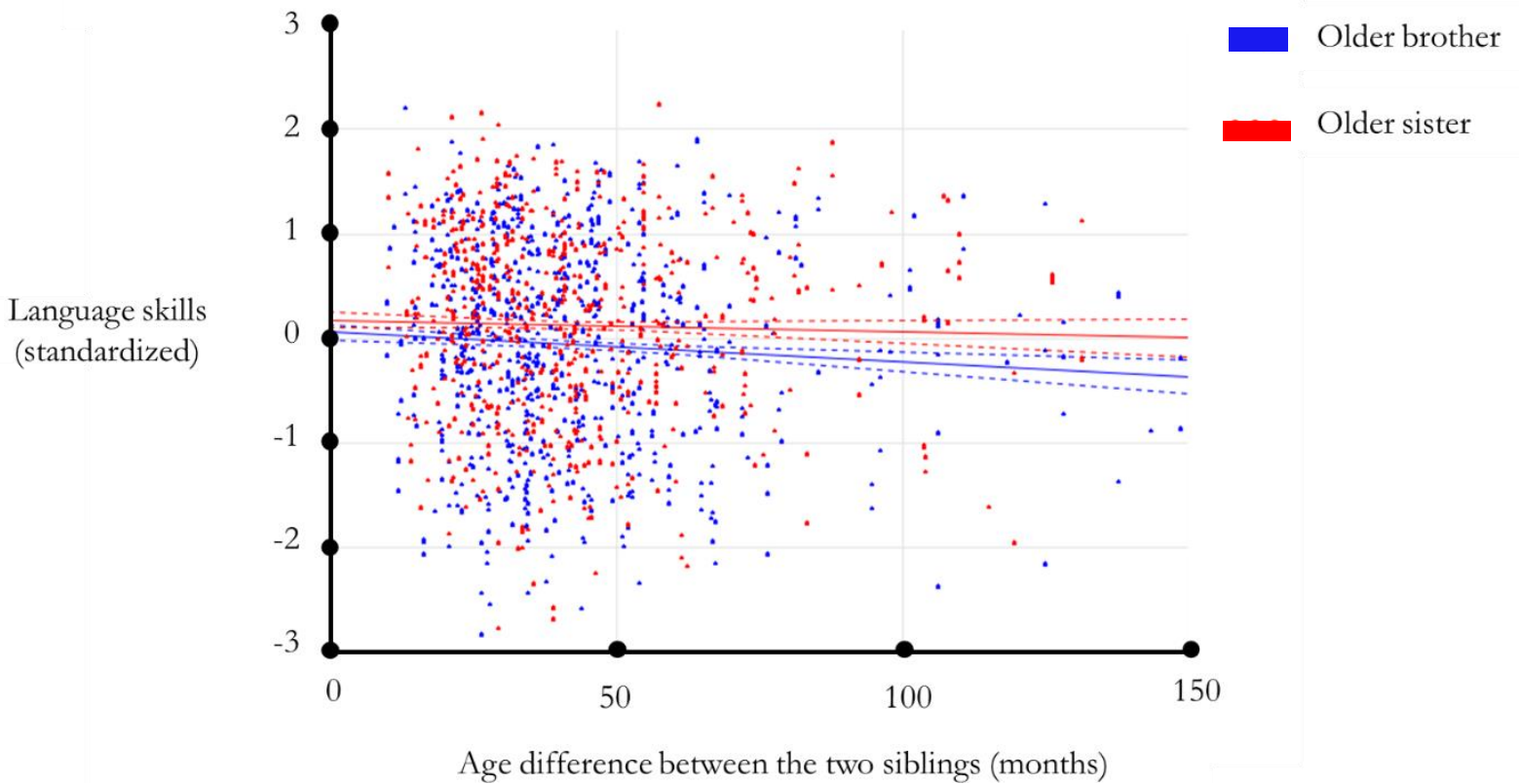

\section{Pre-registered follow-up analyses.}

Children with an older sister had similar language skills to children without an older sibling, while children with an older brother had significantly worse language skills (see Table $\mathbf{4}$ and Fig. 3).

Table 5. Linear mixed regression models with language skills as dependent variable and the presence and sex of the older sibling as independent variable $(\mathrm{N}=1,276)$. 
Language scores\#

At 2 years: $\mathrm{N}=1154$ (with an older sibling: $\mathrm{N}=483$ )

At 3 years: $\mathrm{N}=996$ (with an older sibling: $\mathrm{N}=416$ )

At 5-6 years: $\mathrm{N}=898$ (with an older sibling: $\mathrm{N}=381$ )

\section{Unadjusted model}

Older brother (ref.: without an older sibling)

\begin{tabular}{|c|c|c|}
\hline$\beta$ & SD & $\mathrm{p}$-value \\
\hline-0.234 & 0.037 & $<0.0001$ \\
\hline-0.042 & 0.040 & 0.2969 \\
\hline-0.267 & 0.045 & $<0.0001$ \\
\hline-0.060 & 0.047 & 0.2085 \\
\hline
\end{tabular}

Older sister (ref.: without an older sibling)

Adjusted mode $¥ 1$

Older brother (ref.: without an older sibling)

0.047

0.2085

In bold: p-value < 0.05. \# Z-scores. ¥1 Adjusted for exact age at time of evaluation and other predictors of cognitive development (i.e. sex, gestational age (weeks), birth weight $(\mathrm{kg})$, maternal age at delivery (years), paternal age at delivery (years), breastfeeding initiation (\%), alcohol during pregnancy (units/week), tobacco during pregnancy (\%), parental education (years), household income (k€/month), presence of younger sibling(s) at the time of evaluation).

Figure 3. Language skills of children with no older siblings compared to those with one older brother, and one older sister. The box encompasses the within quartile range, the black star is the mean and the bars are 2 standard deviations.

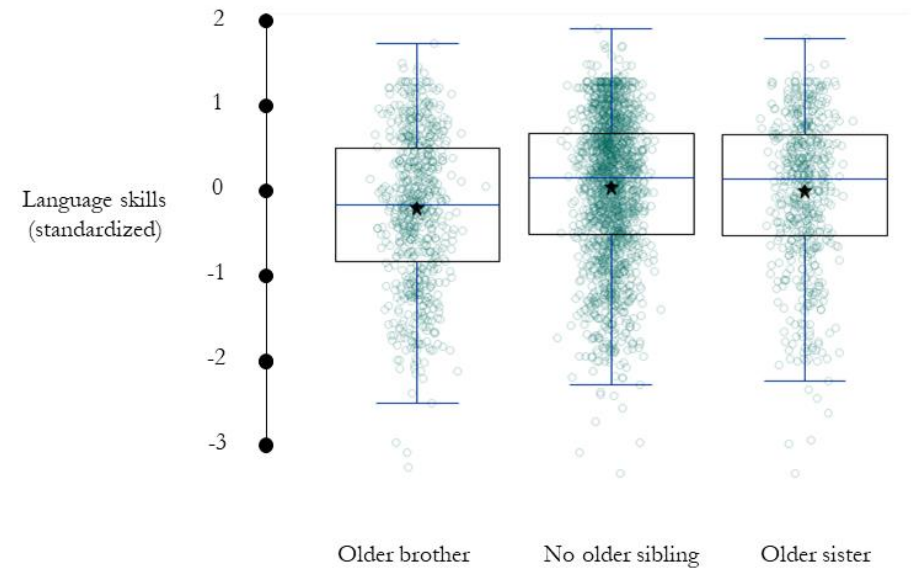




\section{DISCUSSION}

Having an older sibling is associated with lower verbal skills than having no older sibling (e.g., Black, Devereux, \& Salvanes, 2005). We reanalyzed data from the EDEN cohort to examine the effect of the sex of the older sibling and the age gap between siblings on the younger child's language development, reasoning that some older siblings are more likely to compensate for parental resources than others.

Our hypothesis that children with older sisters would have higher language scores than children with older brothers was confirmed. The size of the effect of sibling sex, $d=0.22$, while small, is not negligible in epidemiological studies on cognitive development. It would be the equivalent of three IQ points, and is similar to the birth-order effect in Kristensen and Bjerkedal's seminal study (2007). In a follow-up comparison separating siblings by sex, we found that, while having an older brother was associated with lower language skills than having no older sibling, children who had an older sister scored comparably to children with no older sibling. It thus might be more accurate to think of the well-established negative older-sibling effect as an older-brother effect.

It is unclear whether older sisters help language development - or just hinder it less than older brothers. Indeed, there are two possible reasons for this effect: First, as argued in the introduction, older sisters may themselves contribute to their younger sibling's language development. Older sisters may be more predisposed or better trained to act as caregivers than older brothers (Cole \& Wayne, 1990; Tucker et al., 2001) - or even simply more talkative or willing playmates. Young girls are also more linguistically advanced than young boys until age five-to-six (Peyre et al., 2019), and thus they may be better able to provide quality input. An alternative explanation came to mind after seeing the results: An older brother may be more demanding for parents than an older sister, at the expense of the younger sibling. Mothers of infant boys experience more stress than mothers of infant girls (Scher \& Sharabany, 2010). 
Later on, boys show more externalizing behavior, and tend to be more irritable (Leaper, 2002). This could mean that there is less competition for parental resources from an older sister than from an older brother. While our results cannot discriminate between these two explanations, both focus on the linguistic environment available to the child, and the type of linguistic experiences and input they are exposed to in their early years of life. Our results thus join a vast literature on the effect of the quantity and quality of input on language development (e.g., Ramirez-Esparza, et al., 2014).

We additionally hypothesized that the age gap between siblings will be positively correlated with language scores. This hypothesis was not supported. If anything, we found a trend in the opposite direction: The more closely spaced the siblings were, the higher the language scores of the target child. Thus, although the present study was well powered, the agegap effect remains uncertain. An even larger study would be necessary to determine whether there is a genuine negative age-gap effect or not. This result fails to support the confluence model discussed in the introduction, which stated that the older the sibling, the higher their intellectual abilities and thus the less disruptive they are to their younger siblings' development (Zajonc \& Markus, 1975).

A limitation of the current study is that demographic characteristics of the older siblings were used as a proxy for the level of stimulation the older sibling would provide the younger sibling, as well as for the level of competition. We have no direct evidence that the interactions between children and their older sisters were any different than children's interactions with their older brothers, or that the interactions between caregiver and key child differed in the presence of an older brother compared to an older sister. Moreover, our results drew from the French population, and may not generalize to other cultures. Indeed, Frank, Braginsky, Marchman, and Yurovsky (in prep., see also Steelman, Powell, Werum \& Carter, 2002) found large variability in the birth-order effects across different countries, compared with, for 
example, stability in the female advantage in early language development. Another limitation is that our sample of children with and without an older siblings differed in their demographic characteristics (e.g., children with no older sibling tended to also have fewer younger siblings). While these factors were adjusted for statistically, future studies could try to find a more balanced sample.

To conclude, the current study found that having a sister was associated with higher language scores than having a brother. Children who had an older sister scored similarly to children with no older sibling, while children who had an older brother scored significantly lower. We found no evidence that a larger age gap between siblings was beneficial for the language development of the younger one. 


\section{REFERENCES}

Anthony, L. G., Anthony, B. J., Glanville, D. N., Naiman, D. Q., Waanders, C., \& Shaffer, S. (2005). The relationships between parenting stress, parenting behaviour and preschoolers' social competence and behaviour problems in the classroom. Infant and Child Development: An International Journal of Research and Practice, 14(2), 133-154. https://doi.org/10.1002/icd.385

Bernard, J. Y., Armand, M., Peyre, H., Garcia, C., Forhan, A., De Agostini, M., ... Heude, B. (2017). Breastfeeding, polyunsaturated fatty acid levels in colostrum and child intelligence quotient at age 5-6 years. The Journal of Pediatrics, 183, 43-50.e3. https://doi.org/10.1016/j.jpeds.2016.12.039

Black, S. E., Devereux, P. J., \& Salvanes, K. G. (2005). The more the merrier? The effect of family size and birth order on children's education. The Quarterly Journal of Economics, 669-700. https://doi.org/10.1093/qje/120.2.669

Blake, J. (1981). Family size and the quality of children. Demography, 18(4), 421-442. https://doi.org/10.2307/2060941

Bridges, K., \& Hoff, E. (2014). Older sibling influences on the language environment and language development of toddlers in bilingual homes. Applied psycholinguistics, 35(2), 225-241. https://doi.org/10.1017/S0142716412000379

Buist, K. L., Dekovi, M., Meeus, W., \& Aken, M. A. G. Van. (2002). Developmental patterns in adolescent attachment to mother, father and sibling. Journal of Youth and Adolescence, 31(3), 167-176.

Caldwell, B. M., \& Bradley, R. H. (1984). Administration manual: HOME observation for measurement of the environment. University of Arkansas at Little Rock.

Cole, L., \& Wayne, F. (1990). Children's nurturant interactions with their infant siblings: An exploration of gender differences and maternal socialization. Sex Roles, 22, 43-57. 
https://doi.org/10.1007/BF00288153

De Agostini, M., Metz-Lutz, M.N., Van Hout, A., Chavance, M., Deloche, G., Pavao-Martins, I., \& Dellatolas, G. (1998). Batterie d'évaluation du langage oral de l'enfant aphasique (ELOLA) : standardisation française (4-12 ans). In Revue de neuropsychologie (Vol. 8, pp. 319-367). ADRSC.

Donders, A. R. T., van der Heijden, G. J. M. G., Stijnen, T., \& Moons, K. G. M. (2006). Review: a gentle introduction to imputation of missing values. Journal of Clinical Epidemiology, 59(10), 1087-1091. https://doi.org/10.1016/j.jclinepi.2006.01.014 Duncan, T. G. S. (2017). How Does Maternal Education Influence Language Acquisition? Interdependencies between Environment and Input in the Bilingual Development of Immigrant and Refugee Children (unpublished doctoral dissertation) University of Alberta.

Dunn, J., \& Kendrick, C. (1982). The speech of two- and three-year-olds to infant siblings: 'Baby talk' and the context of communication. Journal of Child Language, 9, 579-595. https://doi.org/10.1017/S030500090000492X

Dunn, J., \& Shatz, M. (1989). Becoming a conversationalist despite (or because of) having an older sibling. Child Development, 399-410. DOI: 10.2307/1130985

Eriksson, M., Marschik, P. B., Tulviste, T., Almgren, M., Pérez Pereira, M., Wehberg, S., ... \& Gallego, C. (2012). Differences between girls and boys in emerging language skills: Evidence from 10 language communities. British Journal of Developmental Psychology, 30(2), 326-343. https://doi.org/10.1111/j.2044-835X.2011.02042.x

Frank, M. C., Braginsky, M., Marchman, V., and Yurovsky, D. (in prep). Variability and Consistency in Early Language Learning: The Wordbank Project.

Hart, B., \& Risley, T. R. (1995). Meaningful differences in the everyday experience of young American children. Baltimore, MD: Paul H Brookes.

Heude, B., Forhan, A., Slama, R., Douhaud, L., Bedel, S., Saurel-Cubizolles, M.-J., ... Thiebaugeorges, O. (2016). Cohort Profile: The EDEN mother-child cohort on the prenatal and early postnatal determinants of child health and development. International Journal of Epidemiology, 45(2), 353-363. https://doi.org/10.1093/ije/dyv151 
Hoff, E. (2006). How social contexts support and shape language development. Developmental Review, 26(1), 55-88. https://doi.org/10.1016/j.dr.2005.11.002

Hoff-Ginsberg, E. (1998). The relation of birth order and socioeconomic status to children's language experience and language development. Applied Psycholinguistics, 19(04), 603. https://doi.org/10.1017/s0142716400010389

Huttenlocher, J., Vasilyeva, M., Waterfall, H. R., Vevea, J. L., \& Hedges, L. V. (2007). The varieties of speech to young children. Developmental Psychology, 43(5), 1062-1083. https://doi.org/10.1037/0012-1649.43.5.1062

Iacovou, M. (2001). Family composition and children's educational outcomes (ISER Working Paper Series No. 2001-12).

Kemp, S. L., Kirk, U., \& Korkman, M. (2001). Essentials of NEPSY Assessment (1st ed.). Wiley.

Korkman M, Kirk U, \& Kemp S. (2003). Nepsy Bilan Neuropsychologique de l'enfant. Paris: ECPA (Editions du Centre de Psychologie Appliquée).

Kern, S., Langue, J., Zesiger, P., \& Bovet, F. (2010). Adaptations françaises des versions courtes des inventaires du développement communicatif de MacArthur-Bates. ANAE. Approche neuropsychologique des apprentissages chez l'enfant, (107-108), 217-228.

Kristensen, P., \& Bjerkedal, T. (2007). Explaining the relation between birth order and intelligence. Science, 316(5832), 1717. https://doi.org/10.1126/science.1141493

Leaper, C. (2002). Parenting boys and girls. In M. H. Bornstein (Ed.), Handbook of parenting, Vol. 1: Children and parenting (pp. 189-225). Hillsdale, NJ: Erlbaum.

Mannle, S., Barton, M., \& Tomasello, M. (1992). Two-year-olds' conversations with their mothers and preschool-aged siblings. First Language, 12, 57-71. https://doi.org/10.1177/014272379201203404

Oshima-Takane, Y., Goodz, E., \& Derevensky, J. L. (1996). Birth order effects on early 
language development: Do secondborn children learn from overheard speech? Child Development, 67(2), 621-634. https://doi.org/10.1111/j.1467-8624.1996.tb01755.x

Perez-Granados, D. R., \& Callanan, M. A. (1997). Conversations with mothers and siblings: children's semantic and conceptual development, Developmental Psychology, 33(1), 120-134. DOI: 10.1037//0012-1649.33.1.120

Peyre, H., Bernard, J., Hoertel, N., Forhan, A., Charles, M., De Agostini, M., ... Study, T. E. G. M.-C. C. (2016). Cognitive Development Differential effects of factors influencing cognitive development at the age of 5-to-6 years. Cognitive Development, 40, 152-162. https://doi.org/10.1016/j.cogdev.2016.10.001

Peyre, H., Galera, C., Waerden, J. Van Der, Hoertel, N., \& Bernard, J. Y. (2016). Relationship between early language skills and the development of inattention / hyperactivity symptoms during the preschool period: Results of the EDEN mother-child cohort. BMC Psychiatry, 1-11. https://doi.org/10.1186/s12888-016-1091-3

Powell, B., \& Steelman Carr, L. (1990). Beyond sibship size: Sibling density, sex composition, and educational outcomes. Social Forces, 69(1), 181-206. https://doi.org/10.1093/sf/69.1.181

Ramírez-Esparza, N., García-Sierra, A., \& Kuhl, P. K. (2014). Look who’s talking: speech style and social context in language input to infants are linked to concurrent and future speech development. Developmental Science, 17(6), 880-891. https://doi.org/10.1111/desc.12172.Look

SAS Institute Inc., SAS 9.1.3 Help and Documentation, Cary, NC: SAS Institute Inc., 20022004

Scher, A., \& Sharabany, R. (2010). Parenting anxiety and stress: Does gender play a part at 3 months of age? The Journal of Genetic Psychology,1325(2), 203-214. https://doi.org/10.3200/GNTP.166.2.203-214 
Shneidman, L. A., Arroyo, M. E., Levine, S. C., \& Goldin-Meadow, S. (2013). What counts as effective input for word learning? Journal of Child Language, 40, 672-686. https://doi.org/10.1017/S0305000912000141

Steelman, L. C., Powell, B., Werum, R., \& Carter, S. (2002). Reconsidering the Effects of Sibling Configuration: Recent Advances and Challenges. Annual Review of Sociology, 28(1), 243-269. https://doi.org/10.1146/annurev.soc.28.111301.093304

Tucker, C. J., Mchale, S. M., \& Crouter, A. C. (2001). Conditions of Sibling Support in Adolescence. Journal of Family Psychology, 15(2), 254-271. https://doi.org/10.1037//O893-3200.

Wechsler, D. (1967). Wechsler Preschool and Primary Scale of Intelligence-3rd edition. San Antonio, TX: The Psychological Corporation.

White, N., Ensor, R., Marks, A., Jacobs, L., \& Hughes, C. (2014). “It's Mine!” Does sharing with siblings at age 3 predict sharing with siblings, friends, and unfamiliar peers at age 6? Early Education and Development, 25(2), 185-201. https://doi.org/10.1111/j.1469$\underline{7610.2010 .02276 . x}$

Zajonc, R. B., \& Markus, G. B. (1975). Birth order and intellectual development. Psychological Review, 82(1), 74-88. https://doi.org/10.1037/h0076229 